\title{
Effect of chemotherapy on the histological appearances of testicular teratoma metastatic to the lung: correlation with patient survival
}

\author{
M MADDEN, P GOLDSTRAW, B CORRIN \\ From the Brompton and Royal Marsden Hospitals, London SW3
}

SUMMARY We report on 20 patients with teratoma of the testis metastatic to the lungs who underwent surgical enucleation of the pulmonary metastases. Seven patients showed predominantly undifferentiated tumour in the pulmonary metastases; six of these died within 26 months, while the seventh was lost to follow up. Four patients showed only scarring or total necrosis of their pulmonary lesions. These patients all received full courses of chemotherapy before surgery and are alive and well with no evidence of recurrence up to four years after diagnosis. In nine patients the pulmonary nodules consisted entirely of well differentiated tissues of benign appearance, sometimes resembling primary pulmonary adenochondromas. These patients also received full courses of chemotherapy before surgery; one died of disseminated disease but the other eight are all alive and well with survival intervals of up to 14 years after presentation.

These findings show that following chemotherapy, necrosis and differentiation of teratomatous pulmonary metastases signify a good prognosis.

Chemotherapy is now standard treatment for patients with metastic testicular teratoma, and cure rates of more than $70 \%$ may be achieved. ${ }^{1-5}$ After chemotherapy residual metastases are not uncommon, and if practical, surgical resection of residual tumour in the retroperitoneum and lungs should be undertaken. Persistent radiological opacities in the lungs may represent metastatic tumour resistant to drug treatment, masses of totally necrotic chemosensitive tumour, or well differentiated teratoid tumours of benign histological appearance. These features are thought to relate to prognosis, ${ }^{6-9}$ and can be assessed only by the histopathologist examining the resected specimens. This paper reports on the histological appearances of resected pulmonary metastases from 20 patients with testicular teratoma and correlates these appearances with patient survival.

\section{Patients and methods}

Over the period 1971-82, 20 patients with teratoma of the testis treated by orchidectomy followed by chemotherapy or radiotherapy or both underwent

Accepted for publication 17 July 1984 thoracotomy at the Brompton Hospital for the enucleation of residual or freshly developing pulmonary metastases. Using the British Testicular Tumour Panel Classification, ${ }^{10}$ we have reviewed the histological appearances of their primary and metastatic tumours and correlated these with patient survival. Many of our cases were referred from other hospitals after orchidectomy, and it is uncertain how well these primary tumours were sampled. The number of sections from the testicular tumours varied between 2 and 12. Details of patient treatment are to be published elsewhere.

\section{Results}

The primary testicular tumours were classified as malignant teratoma undifferentiated $(n=11)$, malignant teratoma intermediate $(n=7)$, or malignant teratoma trophoblastic $(n=2)$. In 10 cases malignant teratoma was combined with seminoma or yolk sac tumour. Because we were examining referred sections, we cannot exclude differentiated elements having been present in the cases classified as undifferentiated.

After treatment the pulmonary modules showed one of three histological patterns: 


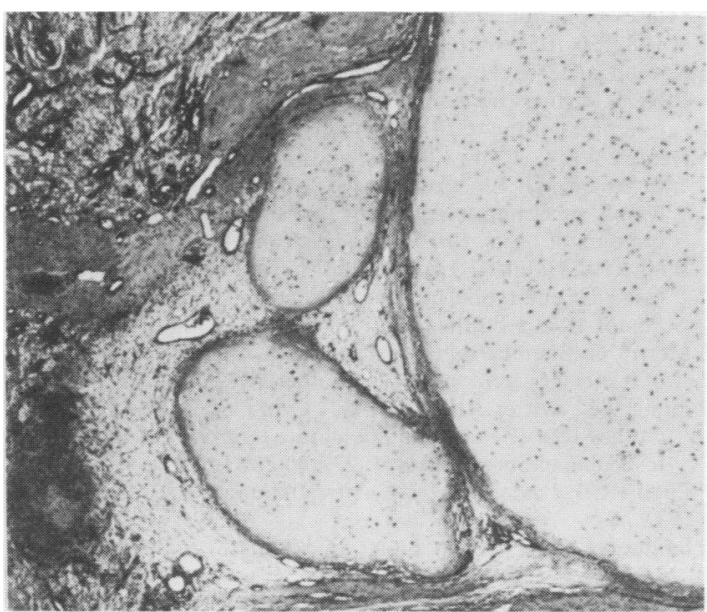

Fig. 1 Pulmonary metastasis after chemotherapy, consisting largely of cartilage of benign appearance. Haematoxylin and eosin $\times 24$.

1 In the first group $(n=7)$ the pulmonary metastases consisted of totally anaplastic tumour, except for one case in which there was also trophoblastic differentiation. Six of these patients died within 26 months, while the seventh was lost to follow up. Four patients in this group received no chemotherapy; in three of these radiotherapy was limited to para-aortic lymph nodes and only one had irradiation to the pulmonary metastases. The other three patients in this group were treated by chemotherapy but did not complete a full therapeutic regimen because of poor clinical response.

2 In the second group $(n=4)$ the resected pulmonary nodules showed only scarring or necrosis and no viable tumour was identified. These patients all received full courses of chemotherapy and are alive and well with no evidence of recurrence two to four years after diagnosis.

3 In the third group $(n=9)$ the pulmonary metastases consisted of mature tissue only and were of benign histological appearance. In three of these cases the pulmonary nodules consisted of mature cartilage intersected by clefts lined by respiratory epithelium (Fig. 1); these appearances were deceptively similar to those of a bronchial adenochondroma (adenochondromatoid hamartoma). Other lesions in this group contained islands of mature squamous epithelium, cysts lined by a simple flattened epithelium, or nodules of leiomyomatous appearance (Fig. 2). These patients all received full courses of chemotherapy. One died of disseminated disease, but the remaining eight are all alive and well with survival intervals of up to 14 years after presentation. The longest survivor, however, has recently developed a radiological abnormality which probably represents a further pulmonary metastasis.

\section{Discussion}

Spontaneous maturation of untreated malignant teratomas has been recorded " but must be regarded as exceptionally rare. With chemotherapy, however, benign transformation is now common. Theoretically, this change could be due to either selective destruction of the more malignant elements or the induction of differentiation within these elements. The complete necrosis of some teratomatous deposits after chemotherapy favours the former mechanism. Oosterhuis $e t a^{12}$ and McCartney et $a l^{13}$ also support this mode of action. Oosterhuis et al compared the number of differentiated tissues in the primary and metastatic tumours excised before and after chemotherapy respectively. If the cytotoxic drugs induced differentiation, a greater variety of tissues would be expected in the metastases, whereas the reverse was found. It would therefore appear that chemotherapy acts by selectively destroying the poorly differentiated elements of the tumour. In many of our cases no differentiated elements were identified in the primary tumour, but this is probably a sampling error because most of our cases underwent orchidectomy at other hospitals and we were able to review only referred sections.

The present investigation shows that there is a good correlation between histological response to chemotherapy and survival. Thus of seven patients with no histological response, six died within 26

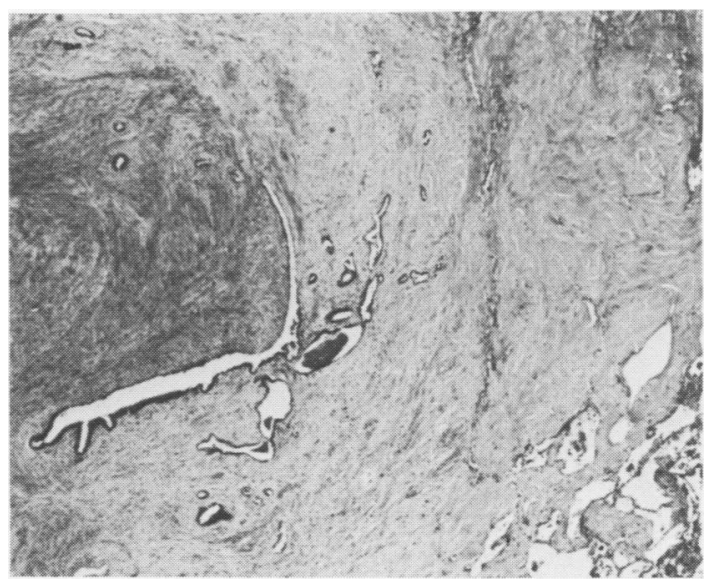

Fig. 2 Pulmonary metastasis after chemotherapy, consisting entirely of mature fibrous tissue and smooth muscle with clefts lined by respiratory epithelium. Haematoxylin and eosin $\times 27$. 
months and the seventh was lost to follow up; of nine patients with well differentiated metastases, eight are alive and well up to 14 years after diagnosis, although the longest survivor has radiological evidence of recurrence; and of four patients without any evidence of viable tumour in their pulmonary metastases, all are alive and well without evidence of recurrence up to four years after diagnosis. This is in agreement with results from other centres. ${ }^{469}$

Benign transformation of teratomas after chemotherapy may present a possible pitfall for the histopathologist unaware of the range of appearances to be found in these lesions, especially if clinical details are withheld. Such well differentiated teratomatous metastases may easily be mistaken for primary thoracic lesions such as pulmonary adenochondromas (chondroid "hamartomas") and bronchogenic or enteric cysts. ${ }^{14} 15$ It therefore behoves the surgical pathologist to be familiar with the benign transformation of malignant teratomas, which is the hallmark of successful chemotherapy.

\section{References}

' Einhorn LH, Donohue J. Cis-diamminedichloroplatinum, vinblastine, and bleomycin combination chemotherapy in disseminated testicular cancer. Ann Intern Med 1977;87:293-8.

${ }^{2}$ Peckham MJ, Barrett A, McElwain TJ, Hendry WF, Raghavan D. Non-seminoma germ cell tumours (malignant teratoma) of the testis: results of treatment and an analysis of prognostic factors. Brit J Urol 1981;53:162-72.

${ }^{3}$ Vugrin D, Herr HW, Whitmore WF Jr, Sogani PC, Golbey RB. VAB-6 combination chemotherapy in disseminated cancer of the testis. Ann Intern Med 1981;95:59-61.

4 Vugrin D, Whitmore WF, Bains M, Golbey RB. Role of chemotherapy and surgery in the treatment of thoracic metas- tases from nonseminomatous germ cell testis tumour. Cancer 1982; 50: 1057-60.

${ }^{5}$ Newlands ES, Begent RHJ, Rustin GJS, Parker D, Bagshawe KD. Further advances in the management of malignant teratomas of the testis and other sites. Lancet 1983; i:948-51.

${ }^{6}$ Hendry WF, Goldstraw P, Husband JE, Barrett A, McElwain TJ, Peckham MJ. Elective delayed excision of bulky para-aortic lymph node metastases in advanced non-seminoma germ cell tumours of testis. Brit J Urol 1981;53:648-53.

7 Willis GW, Hajdu SI. Histologically benign teratoid metastasis of testicular embryonal carcinoma: report of five cases. Am J Clin Pathol 1973;59:338-43.

${ }^{8}$ Merrin C, Baumgartner G, Wajsman Z. Benign transformation of testicular carcinoma by chemotherapy. Lancet 1975;i:43-4.

${ }^{9}$ Hong WK, Wittes RE, Hajdu ST, Cvitkovic E, Whitmore WF, Golbey RB. The evolution of mature teratoma from malignant testicular tumours. Cancer 1977;40:2987-92.

${ }^{10}$ Pugh RCB. Pathology of the testis. Oxford: Blackwell Scientific, 1976.

"Smithers DW. Maturation in human tumours. Lancet 1969;i:949-52.

12 Oosterhuis JW, Suurmeyer AJH, Sleyfer DT, Koops HS, Oldhoff $J$, Fleuren G. Effects of multiple-drug chemotherapy (cis-diamminedichloroplatinum, bleomycin, and vinblastine) on the maturation of retroperitoneal lymph node metastases of nonseminomatous germ cell tumours of the testis: no evidence for de novo induction of differentiation. Cancer 1983;51:408-16.

${ }^{13}$ McCartney AE, Paradinas FJ, Newlands ES. Significance of the "maturation" of metastases from germ cell tumours after intensive chemotherapy. Histopathology 1984;8:457-67.

${ }^{14}$ Snyder RN. Completely mature pulmonary metastasis from testicular teratocarcinoma: case report and review of literature. Cancer 1969;24:810-19.

is Stechmiller B, Wiernik PH, Shin M, Satterfield J. Metastatic teratocarcinoma following chemotherapy: maturation to a mass pathologically indistinguishable from a mediastinal enteric cyst. Chest 1976;69:697-700.

Requests for reprints to: Professor B Corrin, Cardiothoracic Institute, Brompton Hospital, London SW3 6HP, England. 